\title{
PROCESS AND SYSTEMS Implementing and delivering a successful biosimilar switch programme - the Berkshire West experience
}

\author{
Authors: Antoni Chan, ${ }^{\mathrm{A}}$ Joanne Kitchen, ${ }^{\mathrm{B}}$ Amaka Scott, ${ }^{\mathrm{C}}$ David Pollock, ${ }^{\mathrm{D}}$ Richard Marshall ${ }^{\mathrm{E}}$ and Linda Herdman ${ }^{\mathrm{F}}$
}

\section{Background and aims}

Biosimilars used in multiple rheumatic conditions offer the potential for cost savings. We present the outcomes of a service evaluation of switching rheumatic patients established on originator etanercept (Enbrel) to biosimilar Benepali, using a managed switching programme funded through a novel fixed price incentivisation model.

\section{Methods}

Evaluation outcomes included savings in drug acquisition costs, patient-reported side effects, adverse events, patient outcomes and patient experience.

Results

A total of 154 patients on Enbrel were identified for switching. A total of 113 patients ( 43 had rheumatoid arthritis, 43 had axial spondyloarthritis and 27 had psoriatic arthritis) were switched from originator etanercept to Benepali from August 2016 to March 2017. The Royal Berkshire NHS Foundation Trust had the highest percentage of switches in the Thames Valley in this period. There was no increased incidence of side effects before and after switch. Drug acquisition costs were decreased by $£ 95,000$ with an overall reduction in prescribing costs of $£ 186,000$ for the local health economy.

\section{Conclusions}

A managed switching programme from originator etanercept to biosimilar Benepali, using a novel fixed price model, delivers significant cost savings and investment in clinical services while maintaining similar patient-reported outcomes and good patient experience.

KEYWORDS: Etanercept, biosimilars, biologics, switching, Benepali

Authors: ${ }^{\text {A }}$ consultant rheumatologist and associate medical director, Royal Berkshire NHS Foundation Trust, Reading, UK; ${ }^{B}$ consultant rheumatologist, Royal Berkshire NHS Foundation Trust, Reading, UK; ${ }^{C}$ medicines optimisation interface lead pharmacist, NHS Berkshire West Clinical Commissioning Group, UK; ${ }^{\mathrm{D}}$ Clinical integration pharmacist, NHS Berkshire West Clinical Commissioning Group, UK; Ehomecare pharmacist, Royal Berkshire NHS Foundation Trust, Reading, UK; ' Fiologics nurse specialist, Royal Berkshire NHS Foundation Trust, Reading, UK

\section{Introduction}

A biosimilar is a biological medicine which has been shown not to have any clinically meaningful differences from the originator biological medicine in terms of quality, safety and efficacy. ${ }^{?}$ Anti-tumour necrosis factor (TNF) medicines are one of the highest spend areas on high cost drugs, with $€ 780$ million spent across England and $€ 5.42$ million in Berkshire West Clinical Commissioning Group in the last 12 months. ${ }^{2}$ The availability of biosimilar anti-TNFs presents a significant opportunity for the NHS to achieve substantial savings based on a lower acquisition price of $20-50 \%$ against the list price of the originator product. ${ }^{3}$

Enbrel (Pfizer, New York, USA) was the first self-injected anti-TNF that the patient keeps at home that had come off patent, allowing for a switch to a biosimilar, Benepali (Biogen, Cambridge, USA). This presented unique challenges compared to the switching of those on intravenous infliximab, most notably it involved homecare teams and patient training. Logistically, this switch would be more complicated than the infliximab switch. Infliximab is given as an infusion and is generally purchased, prescribed, dispensed and administered within a hospital. Etanercept is delivered through homecare, which means a third party organisation is contracted to dispense etanercept and deliver it to the patient. These additional steps resulted in added complexity when it came to planning this switch programme.

Ahead of the availability of biosimilar etanercept (Benepali) in 2016, a working group consisting of clinicians and stakeholders across Berkshire West (Medicines Optimisation Network, Regional Procurement Pharmacists, Chief Pharmacists Group) was formed to optimise savings opportunities. The aim was to support the switch of patients from originator etanercept (Enbrel) to biosimilar Benepali and to realise savings potential.

\section{Solution/methodology}

Standards were set to optimise the service delivered, steps defined to ensure best patient outcomes and experience as well as the impact on the clinical team evaluated. The clinical standards set out during the switch programme were:

> standardisation of the procurement and formulary process

> consistency in biologics prescribing processes and safety monitoring

> standardised processes in brand name prescribing/dispensing

$>$ defined treatment pathways and protocols, standardised and documented 
> ensure patient outcome measures and data collection processes

$>$ maintain high quality of care for all patients when a biosimilar is prescribed.

The switch programme was started in August 2016 and completed by end March 2017. The five key steps to implementing the biosimilar switch strategy were:

$>$ set up a biosimilar working group

$>$ define the treatment pathway

$>$ run patient-focused initiation

$>$ run a biosimilar monitoring system

$>$ measure and monitor the implementation pathway.

The implementation was carried out in two key phases. The first phase comprised of preparatory work required to safeguard patient safety and included:

> letters (supplementary material S1) and information sheets (supplementary material S2) sent out to patients informing them of the plan to switch to Benepali

> discussed with patients reasons for the switch programme and consent

$>$ educational events were organised for patient information

$>$ following consent being given, the prescription for Benepali was sent to the homecare team in pharmacy for clinical validation and processing.

The second phase of the switch programme involved the managed switch of the patients within the homecare system.

> Each consented patient was contacted to confirm how much Enbrel they had in stock.

> Based on these levels, those patients with lowest stock were prioritised and had their current Enbrel homecare prescription cancelled.

> A new prescription with the homecare company for Benepali was raised and we ensured the next delivery coincided with the level of stock of Enbrel held.

> Patients had a follow-up in clinic 12 weeks after the switch to monitor response effects for the switch.

> Data were collected for audit purposes with administrative support.

> Prescriptions raised were flagged to allow for accurate recharging at the clinical commissioning group (CCG) fixed price model.

\section{Outcome}

We used a fixed price incentivisation model which allows the commissioner to control their spending on etanercept, while giving the trust the opportunity to realise significant savings. The fixed price model (Fig 1) is based around an agreement with the CCG that all brands of a given biologic drug will be recharged at a fixed price for a set period (typically 1 year). This price will be approximately $75 \%$ of the originator price but is dependent upon the price of the biosimilar upon release. The aim is to leave a gap of approximately $6-10 \%$ between the fixed price and the price of biosimilar brand, whereby when patients are switched to the cheaper biosimilar brand, the trust is able to realise $100 \%$ of this savings gap. The trust is able to realise a greater proportion of these savings by carrying out a switch in a time efficient manner. The benefits for the CCG are that they can realise a $25 \%$ saving across the year and ensure that all patients are switched within this time.

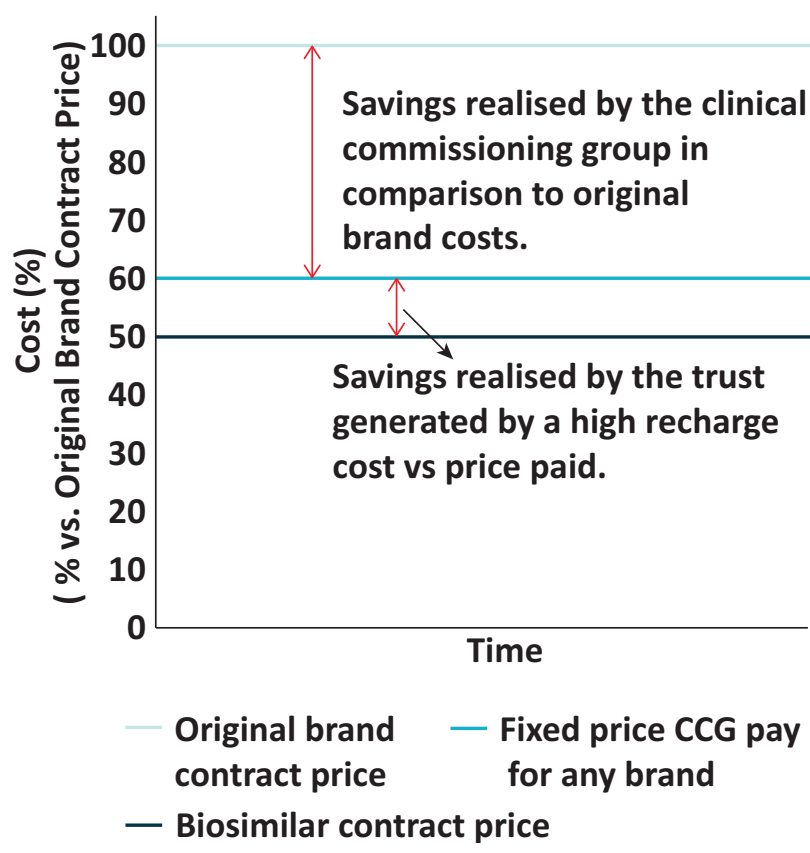

Fig 1. Fixed price incentivisation model for switch from originator to biosimilar drug. The trust = the Royal Berkshire NHS Foundation Trust; the clinical commissioning group $=$ the Berkshire West Clinical Commissioning Group.

During the 2016/17 financial year, the fixed price rechargeable value was $£ 699,806$ and the procurement cost of Benepali was $£ 593,539$. The cost of a Band 7 locum pharmacist for 6 weeks and admin cost was $£ 11,250$. This was the amount of time required to set up the switch programme while cover for pharmacy services were maintained. The saving through the reduction of drug acquisition costs was $£ 95,017$ during the switch programme and this was utilised for the appointment of a long-term biosimilar switch pharmacist.

One-hundred and fifty-four patients on Enbrel were identified and 113 patients switched. The patients that were not switched were due to in availability of Benepali in the $25 \mathrm{mg}$ dose or out of licence indications at the time of the switch. The 113 patients who were on Enbrel for rheumatoid arthritis, ankylosing spondylitis and psoriatic arthritis were switched to Benepali. Four patients switched back to the originator Enbrel due to increased disease activity on assessment. Three patients switched to an alternative biologic and four discontinued therapy due to intolerance of the treatment.

A survey on patient perceptions about switching from originator biologic to biosimilar was carried out in October 2017. The postimplementation pro forma is shown in supplementary material S3. Ninety-four responded ( $47 \mathrm{female}, 47 \mathrm{male}$ ) to the survey. The majority recalled receiving written information about biosimilars $(81 / 94,86 \%)$ and discussing them in clinic $(78 / 94,83 \%)$. Fifty-nine of ninety-four (63\%) had no concerns about switching. Concerns were about efficacy $(27 / 94,29 \%)$, safety $(5 / 94,5 \%)$ and side effects $(3 / 94,3 \%)$. Mean visual analogue score for confidence in the biosimilar was 7.86 (median 8, 1-10). Sixty-two per cent (58/94) reported no problems with the switch. Patient-reported problems included arthritis flare (worsening pain or stiffness $(12 / 94,13 \%)$ increased fatigue $(4 / 36,11 \%)$, painful injections 
$(5 / 94 \%, 5 \%)$ and infections $(2 / 94,2 \%))$ and other (one each of rash, breathlessness, itchy eyes, thumb nodule, abdominal pain and headache).

\section{Conclusions and next steps}

Biosimilars are now available and can provide significant savings for the health economy. The trust had the opportunity to receive a net income of over $£ 95,000$ in the financial year following the switch to Benepali, with an overall reduction in prescribing costs of $£ 186,000$ for the local health economy. In a previous infliximab biosimilar switch, savings made through a 50:50 gain share model. Despite this model allowing for significant savings, it was not a model without risks. The savings were based upon the difference in contract prices between the originator and biosimilar brands. As a result, they are subject to change and so projected savings were at risk of reducing if the contract prices of the originator and biosimilar brands moved towards each other.

As the price of the originator drug is reduced following the introduction of biosimilars, the margin for savings may be too small in a gain share model, necessitating a novel model such at the fixed price incentivisation model. The steps taken to carry out the switch programme will be used for future biosimilar switches. In the previous infliximab switch programme, the trust has not had the sufficient resources to pre-empt the biosimilars coming to market. ${ }^{4}$ As a result we have been unable ensure that switch programmes were implemented from day 1 , so as to maximise the savings.

Following the loss of exclusivity for AbbVie's adalimumab brand, Humira (AbbVie, Lake Bluff, USA), a drug which costs the NHS more than $£ 333$ million a year, NHS England stepped in and produced a framework to maximise the uptake of the biosimilars and, therefore, savings for the NHS. This framework sets a reference price; a fixed price CCGs are recharged for any brand of adalimumab. This price has been set lower than the Humira brand price, but significantly higher than the biosimilar prices. The effect of this is identical to the fixed price model; trusts are incentivised to switch to the biosimilars and can maximise their income by ensuring a fast and efficient switch.

A biosimilar switch pharmacist was also employed to horizon-scan, plan and implement switch programmes for every biosimilar that comes to market, including the current Humira switch programme. NHS England has a target that at least $80 \%$ of existing patients should be switched to the best value biological medicine within 12 months. The lessons that were learnt from the etanercept switch has allowed the Royal Berkshire NHS Foundation Trust to achieve over the $80 \%$ target switches of adalimumab in the first 2 months.

\section{Supplementary material}

Additional supplementary material may be found in the online version of this article at http://futurehospital.rcpjournal.org:

S1 - Patient consent letter.

S2 - Patient information sheet.

S3 - Post-implementation review pro forma.

\section{References}

1 NHS England. What is a biosimilar medicine? NHS, 2015. www.england. nhs.uk/wp-content/uploads/2015/09/biosimilar-guide.pdf.

2 Rx-info. Define data: National comparison of anti-TNF usage, previous 12 months. Exeter: Rx-info, 2018. https://rxinfo.thirdparty. nhs.uk [Accessed 15 October 2018].

3 NHS England. Principles for sharing the benefits associated with more efficient use of medicines not reimbursed through national prices. NHS, 2014. www.england.nhs.uk/wp-content/ uploads/2014/01/princ-shar-benefits.pdf.

4 National Institute for Health and Care Excellence. Introducing biosimilar versions of infliximab: Inflectra and Remsima NICE technology appraisal support. Health technologies adoption programme [HTTA329]. NICE, 2015.

Address for correspondence: Dr Antoni Chan, Royal Berkshire NHS Foundation Trust, Department of Rheumatology, London Road, Reading, Berkshire RG1 5AN, UK.

Email: antoni.chan@nhs.net 